\title{
Alternative Frameworks of the Secondary School Students on the Concept of Condensation at Submicroscopic Level
}

\author{
Nurdiana Abdullah ${ }^{1}$, Johari Surif $^{1} \&$ Syuhaida Ismail ${ }^{2}$ \\ ${ }^{1}$ Department of Educational Sciences, Mathematics and Creative Multimedia, Faculty of Education, University \\ of Technology Malaysia, Malaysia \\ ${ }^{2}$ RAZAK School of Engineering and Advanced Technology, University of Technology Malaysia, Jalan Semarak, \\ Kuala Lumpur, Malaysia \\ Correspondence: Nurdiana Abdullah, Department of Educational Sciences, Mathematics and Creative \\ Multimedia, Faculty of Education, Universiti Teknologi Malaysia, Malaysia. E-mail: cdiana818@gmail.com
}

Received: July 14, 2015 Accepted: November 4, 2015 Online Published: April 26, 2016

doi:10.5539/ies.v9n5p255

URL: http://dx.doi.org/10.5539/ies.v9n5p255

\begin{abstract}
The study was carried out to identify the alternative frameworks on the concept of condensation at submicroscopic level among secondary school students $(\mathrm{N}=324)$. Data was collected by using the qualitative method through the Understanding Test on the Concept of Matter at Submicroscopic Level which consisted of 10 open-ended questions. The analysis of contents showed that the students' alternative frameworks on the concept of condensation at submicroscopic level are divided into three categories namely the explanations with the alternative frameworks at submicroscopic level, the limited explanations at macroscopic level and no explanation. This article discussed the alternative frameworks of the first category only, namely the explanations with the alternative framework at submicroscopic level while the second and third categories are discussed in the second part of the article. In summary, some implications on the teachings are recommended in order to enhance the understanding of the students on the concept of condensation at the submicroscopic level.
\end{abstract}

Keywords: alternative framework, chemistry education, condensation, submicroscopic level, qualitative

\section{Introduction}

Condensation is one of the fundamental concepts in chemistry curriculum and is useful in explaining the phenomena that occurs in everyday life and activities (Kirbulut \& Beeth, 2013). It is one of the changes in states of matter based on the kinetic theory of matter which occurs during the change of heat. Heat is the energy that drives the particles in matter. Therefore, changes in the states of matter can occur through the process of heating or cooling when the heat energy is absorbed or released from matter. Condensation is the change in the state of matter that occurs when the heat is released or undergoes a cooling process. During the cooling process, the heat will be released and the state of matter changes from gas to liquid. The students are introduced to the concept of condensation during their learning at the secondary school level. This concept is in the topic of matter under the sub-topic of the change in state of matter. Fundamental to the understanding of this concept is the mastery by the students of the kinetic theory of matter and this theory is also important to enable the students to explain the characteristics of matter (solid, liquid and gas) (Kheng, 2011). The kinetic theory of matter explains it based on a number of assumptions such as that matter consists of tiny discrete particles and the particles move randomly. The assumptions can be found at the submicroscopic level.

Submicroscopic level refers to the understanding of chemistry at the level of particles which involves molecules, ions, atoms, subatomic particles and others (Colburn 2009). This level is difficult to be mastered by the students (Haidar \& Abraham, 1991; Snir et al., 2003) because of the characteristics of this level which are related to the world of atoms and its derivatives such as ions and molecules. This is because the ions and molecules are worlds that cannot be seen by the organs of human senses and can only be reached through imagination (Bucat \& Mocerino, 2009). In addition, the submicroscopic level also becomes difficult to be mastered by the students when the teachers and students tend to isolate chemistry at school from daily life. As a result, the students develop two systems of knowledge that are not associated with chemistry namely a system that is used to solve the chemistry problems at school and another system is used in their daily lives (Osborn and Freyberg, 1985) while when the chemistry concepts are associated with everyday life during the teaching and learning sessions, 
the retention of the concepts in the minds of students is far better (Demircioğlu et al., 2005).

However, the previous studies showed that students at various ages have alternative frameworks on the concept of condensation (Kruger \& Summers, 1989; Bar \& Travis, 1991; Lee et al., 1993; Chang, 1999; Gopal et al., 2004) covering various topics such as vapor pressure (Gopal et al. 2004), condensation in opened system (Paik et al., 2004), condensation in closed system (Costu, 2006), the concept and the phases of matter (Johnson, 2005) and the development of the students conceptualization in understanding the change of phases (Varelas et al., 2006). For example, a study by Costu et al. (2012) found that first year students in the department of primary science education listed eight difficulties and alternative frameworks namely water vapor cannot be converted to water, water vapor cannot exist in the air at all times, hydrogen and oxygen, the components of water vapor exist in the air other than the water vapor itself, the molecules of water vapor are lighter than the molecules of water, the air is condensed as water, the condensation occurs because the vapor pressure is rising and only water vapor exists in the air during winter and ice on the cold surface will melt and form water droplets (condensation in the opened system).

The alternative framework occurs when the students start building their own concepts and the construction of the concepts is different from what is taught by the teachers. The alternative framework is also a concept that belongs to the students that is not in line with the scientific concept of the scientists (Barke et al., 2009). The existence of this alternative framework is closely related to the inability of the students to explain the chemistry phenomena at the submicroscopic level (Abraham et al., 1994; Abraham et al., 1992; Haidar \& Abraham, 1991) although the students have been asked to think by using this level from the atomic and molecular aspects (Ardac \& Akaygun, 2004). This condition affects the learning of the students when they translate the teachings based on the alternative framework. Therefore, it is important to identify the student alternative framework on the concept of condensation at the submicroscopic level and further develop the teaching strategies that are appropriate to correct the alternative framework.

\section{The Objective of the Study}

This study was conducted to identify the alternative frameworks of form four of science stream students from secondary school through their explanations of the concept of condensation at the submicroscopic level. This study focused on the alternative frameworks among the students since the previous studies showed that the alternative frameworks interfere with the next learning. This means that new knowledge cannot be integrated appropriately into the cognitive structure of the students (Taber, 2000). This concept was selected because some previous researchers showed various problems concerning the understanding of the students on condensation at the submicroscopic level (Varelas et al., 2006; Johnson, 2005; Paik et al., 2004; Hatzinikita \& Koulaidis, 1997). The following study question was investigated in this study: What are the alternative frameworks of the students on the concept of condensation at the submicroscopic level from the aspect of the explanations?

\section{Methodologies}

\subsection{The Design of the Study}

In order for an in-depth collection of the concept of alternative frameworks of condensation at the submicroscopic level based on students explanations, qualitative study method by using the descriptive approach was used in this study. The method and approach were suitable to be used because they were seen as the best strategies to answer the questions in this study. Even through the qualitative approach, the researchers were able to study the phenomena that occurred naturally with all the inherent complexities (Fraenkel \& Wallen, 2006). Moreover, the qualitative study applied inductive analysis and involved specific data (Hittleman \& Simon, 2002).

\subsection{Sample Selection}

A total of 324 form four science stream students in secondary schools were selected randomly for this study. Purposive random sampling technique was used as it was capable of ensuring each subject in the population has an equal chance to be selected to participate in the study (Patton, 2008). A total of four ordinary daily secondary schools and one technical school in Johor Bahru district were involved in this study. The main factor of the selection was that the students have finished learning the concept of condensation during this study. Overall, the students involved were aged from 16 to 17 years.

\subsection{Instrument}

The paper and pencil test which was the Understanding Test on the Concept of Matter at the Submicroscopic Level has been used which included ten items in respect of matter as discrete particles, the composition of particles, the relative spacing between particles, the movement of particles, the existence of attraction forces 
between particles and the existence of vacuum between particles. These items were open-ended questions that required students to give answers in terms of explanations and drawings. Content validity of this test was done by having two chemistry experts do the evaluations.

\subsection{Data Analysis}

The students' answers which were obtained from Understanding Test on the Concept of Matter at the Submicroscopic Level instrument were analyzed qualitatively by using content analysis technique. Through this technique, students' answers were classified into scientific concept, alternative framework and no answer (Abraham et al., 1994; Ayas \& Ozmen, 2002; Ayas et al., 2010; Costu, 2008). Answers were then coded according to specific themes. These categories are explained in detail in Table 1. A total of two chemistry experts were asked to confirm the themes constructed by the researchers.

Table 1. The categories to classify the students' answers

\begin{tabular}{ll}
\hline Category & Criteria for classification \\
\hline Scientific concept & $\begin{array}{l}\text { Students' answers which include the understanding criteria of the scientific concept } \\
\text { Alternative }\end{array}$ \\
framework & $\begin{array}{l}\text { Students' answers which include an understanding of the subset of concepts that } \\
\text { contradict the scientific aspects }\end{array}$ \\
No answer & $\begin{array}{l}\text { There is no evidence or insufficient evidence to assess students' understandings as } \\
\text { scientific understandings }\end{array}$ \\
\hline
\end{tabular}

\section{Findings and Discussions}

The findings are as follows:

The study found that students' alternative frameworks on the concept of condensation at submicroscopic level from the aspect of explanations are divided into the explanations with alternative frameworks at submicroscopic level (11.11\%), limited explanations at macroscopic level (19.14\%) and no explanation (44.44\%).

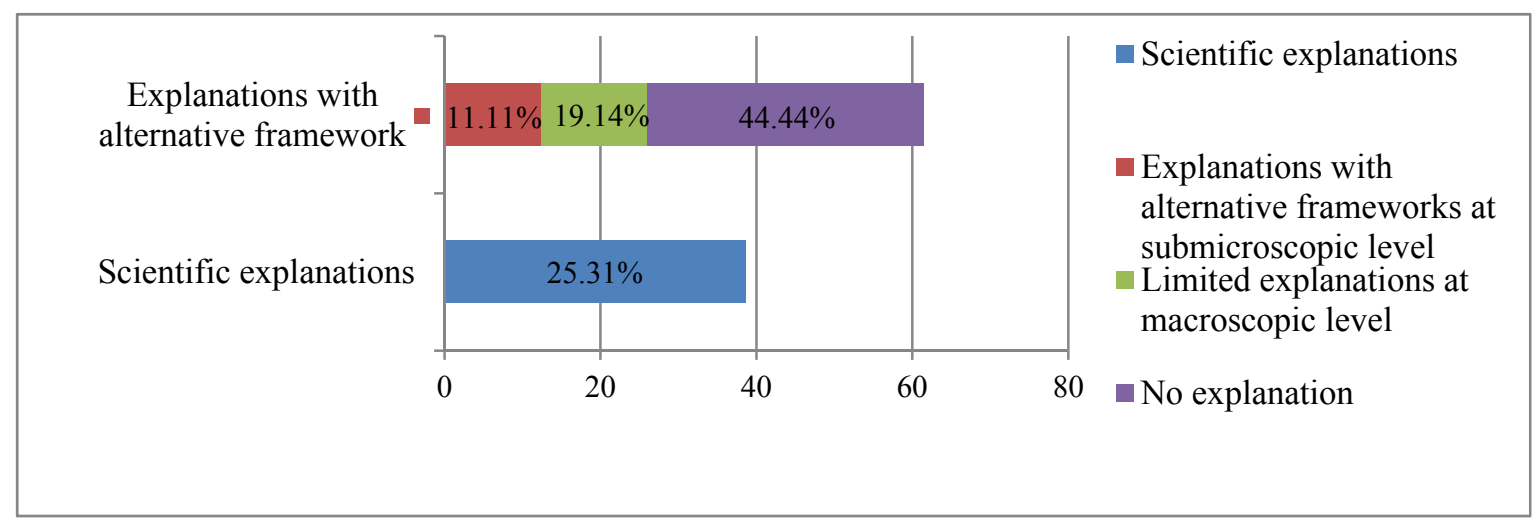

Figure 1 Scientific explanation and explanations with alternative framework on the concept of condensation at submicroscopic level

\subsection{The Students' Explanations with Alternative Frameworks at Submicroscopic Level}

The findings showed that the aspect of students' explanations with the alternative frameworks at the submicroscopic level representing 11.11 percent can be broken down into ten sub-categories, namely the formation of molecules caused by combinations between the particles and not by the formation of bonds, particles of air turn into liquid, alternative frameworks from the movement of particles aspect, confusion about the characteristics of particles of matter, the change of phase from gas to liquid due to bond cleavage, reducing number of particles, the particles become compressed and gathered in one area, the distance between particles is long, condensation as energy absorption by the particles and the confusion of the attraction force between particles (refer Table 1). The details of students' explanations with the alternative frameworks at the 
submicroscopic level are as follows:

Table 1. Summary of students' explanations with alternative frameworks at submicroscopic level

\begin{tabular}{|c|c|c|}
\hline \multirow{2}{*}{ Students' Explanations with Alternative Frameworks at Submicroscopic Level } & \multicolumn{2}{|c|}{ Score } \\
\hline & $\mathrm{N}$ & $\%$ \\
\hline $\begin{array}{l}\text { The formation of molecules caused by combinations between particles and not by the formation } \\
\text { of bonds }\end{array}$ & 7 & 2.16 \\
\hline Air particles change into liquid & 7 & 2.16 \\
\hline The alternative framework from the aspect of movement of particles & 3 & 0.93 \\
\hline Confusion about the characteristics of matter & 1 & 0.31 \\
\hline Change of phase from gas to liquid due to bond cleavage & 1 & 0.31 \\
\hline Reducing number of particles & 4 & 1.23 \\
\hline The particles become compressed and gathered in one area & 4 & 1.23 \\
\hline The distance between the liquid particles is long & 4 & 1.23 \\
\hline Condensation as energy absorption by particles & 3 & 0.93 \\
\hline Confusion about the attraction forces between the particles & 1 & 0.31 \\
\hline Total & 35 & 11.11 \\
\hline
\end{tabular}

4.1.1 The Formation of Molecules Caused by Combinations between the Particles and Not by the Formation of Bonds

The findings of the study indicate that 2.16 percent of students' answers were categorized as the formation of molecules caused by the combination between particles as the most influential alternative framework among the students compared to other aspects, not by the formation of bonds. This was because the students often used the alternative framework of this aspect when explaining the phenomena of gas condensation. The following explanation was provided by the students:

Gas particles will be reduced and combined with the cooling of gas to liquid

(Students aged 16-17 years)

The students' answers indicated the existence of alternative framework among the students on the concept of chemical bonds between the particles. The alternative framework was seen as very significant when the students used the words or terms which were not accurate such as 'join', 'stick', 'attach' and 'merged' in describing the concept of the chemical bonds that exist between particles. This occurred because the concept was less disclosed and emphasized to the students by the teachers during the teaching and learning sessions, other than that the students were confused by the words they use in everyday life. The findings of this alternative framework are not surprising because the studies by Kirbulut and Teeth (2013) based on Lisa's study found that she also did not specify the role of chemical bonds when discussing the phenomena of evaporation although she mentioned that the water molecules will be split (break apart) to hydrogen and oxygen gasses in her verbal statements and drawings for the phenomena of evaporation. In addition, Lisa did not state that the intermolecular forces such as hydrogen bonds would hold water molecules together. This condition occurred because the chemical bonds concept was too abstract for the students and it was difficult for them to master this concept very well.

\subsubsection{Air Particles Change into Liquid}

The frequency of students who considered the air particles change into liquid form was proven when 2.16 percent discussed this alternative framework in their explanations. This situation occurred when students mixed the explanations of the submicroscopic level (air particles) with the macroscopic level (change into liquid). This is proven from the answer given by one of the students:

When the gas is cooled, the molecules present in the gas are converted into liquid. This is because the levels of activities are decreasing and the molecules are shrinking 
From the answer, it was obvious that the students were confident that the gas particles were undergoing the process of heat release which was the cooling that will change to the liquid state. In addition, an interesting alternative framework to be discussed in this sub-category is related to the change in the sizes of particle entities. The students talked about the shrinking molecules when gas molecules were cooled down. The explanations of these students showed that the macroscopic characteristics interfered with the perception of matter at the submicroscopic level. This was in line with the findings of the previous study by Gabel et al. (1987) which was that the science teachers in primary schools considered that the atom is increasing in size when changing from liquid to gas and are not moving further apart. Additionally, the gas particles were also described as orderly and not in a state of disorganization. Among the causes of the occurrence of an alternative framework was that the students usually described the phenomena based on intuition rather than based on chemistry concepts unless stimulated and encouraged to do so. The study by Taber (2001) also reported that it was common for students to make statements such as 'Matter melts due to the melted molecules'.

\subsubsection{The Alternative Framework from the Aspect of Movement of Particles}

Although the aspect of the movement of particles dominated the scientific concept of the students' explanations, this aspect has also become an alternative framework among the students by 0.93 percent. This means that only a small number of students were confused by this aspect when explaining the phenomena of condensation of gas. This confusion is clear from the following answer:

When the cooling of gas occurs, the high air pressure applied to the gas particles cause the particles often collide with each other

(Students aged 16-17 years)

An alternative framework of this aspect occurred when the students understood the concept of movement of particles that was wrong, for example by assuming that the particles collided with each other when the cooling of gas occurred. In addition, the students were also found to state that the particles move quickly when the particles become hot. The explanation is consistent with the findings of Novice and Nussbaum (1981) and Mitchell and Kellington (1982) which stated that 50 percent and 81 percent of the students knew that the energy or the movement of particles increased with the increasing temperature and 30 percent and 68 percent were aware otherwise that the cooling led to the reduction of movement of particles.

\subsubsection{The Confusions on the Characteristics of Matter}

Although the students were aware the phenomena that occurred was the phenomena of condensation, a total of 0.31 percent of answers given by the students showed confusion on the characteristics of particles of matter. Among the answers are as follows:

The temperature will slow down their movement and will cause them to freeze

(Students aged 16-17 years)

The students' answers showed that the students used the observations at the macroscopic level to characterize the behaviour of the particles at the submicroscopic level. The students simply stated that the phenomena that occurred was condensation but did not describe in detail the processes that took place. This matter revealed that the students were only able to state the processes and the reactions that occurred but did not explain specifically the processes and the reactions. This situation showed that the students were able to state the answers accurately to these questions but gave the wrong explanations. This situation also occurred during the interviews conducted in the study of Yalçinkaya and Boz (2015) on the concept of gas which was under Charles Law with the students in grade 10 in Ankara, Turkey.

\subsubsection{The Change of Phase from Gas to Liquid Due to the Bond Cleavage}

Only a small number of students had the alternative framework for this aspect which was for only 0.31 percent. Example of such explanation is as follows:

Atom gas lost heat energy to break the bond

(Students aged 22-23 years)

The students' answers showed that they were confused with the concept of energy loss of particles on chemical bonds between the particles. In a gaseous state, attraction forces or chemical bonding between the particles are negligible. This finding is not surprising because for a long time in the field of science education studies showed the existence of alternative framework on this aspect to students. For example, the students considered bond formation as endothermic whereas bond breaking was considered as exothermic, and also some students had an 
alternative conception that bond formation and breaking were exothermic (Boo, 1998; Barker \& Millar, 2000).

\subsubsection{Reducing Number of Particles}

Only 1.23 percent of students had the alternative framework on the number of particles aspect and the explanation given is as follows:

The particles become lesser and can move freely

(Students aged 16-17 years)

The students' answers indicated the existence of alternative framework among the students when describing the number of particles reducing due to the cooling process that occurred and increased when the gas turned into the liquid state. This alternative framework can be attributed to the incorrect understanding of the students of the concept of conservation of particles. A similar situation also occurred in the study by Gabel and Samuel (1987) when a total of 50 percent of students ignored this concept when drawing up diagrams at the submicroscopic level. This situation occurred as a result of negligence or whether the students were not aware that the particles were experiencing the conservation concept.

\subsubsection{The Particles Become Compressed and Gathered in One Area}

A total of 1.23 percent of students was confused by this aspect in their answers. The confusion was proven in the following explanation:

This process is called condensation. The cooling process makes the particles stop at the side of the conical flask and as it accumulates it liquefies and drips down to the bottom of the conical flask

(Students aged 16-17 years)

The state of particles becoming the alternative framework occurred when the students stated the change in the state of the particles at the level of macroscopic such as particles that were compressed or gathered in one part of the flask. This alternative framework also occurred in the study of Smith and Villarreal (2015) when the majority of the students (41-44 percent) considered molecules that were black would not move away from the original position while in the solid state even though they had melted. This situation demonstrated that the students had an alternative conception of the idea that molecules moved around within the volume occupied by the liquid.

\subsubsection{The Distance between the Liquid Particles is Far}

For the scientific concept, the distance of particles aspect was the one most mastered by the students. The situation did not occur in this section when students showed the existence of alternative framework on this aspect. However the percentage for this aspect was insignificant and was not worrying about at only 1.23 percent. The alternative framework occurred when the students expressed the following:

After it is cooled off and changed into liquid, the distance between the particles is farther because the liquid is a moderate mass and the movement is year

(Students aged 16-17 year)

The answer above proved that the students still considered the distance between the liquid particles was between the distance of solid particles and the distance of gas particles whereas the right distance ratio according to de Vos and Verdonk (1987) was 1:1:10. However, this finding was not surprising since the literature showed significant confusion occurred to the students in terms of the distance of particles in liquid state, for example in the studies of Johnson (1998), Johnston (1990), Lee et al. (1993), Pereira and Pestana (1991), Scott (1992) and Stavy (1988).

\subsubsection{Condensation as Energy Absorption by Particles}

Condensation as the absorption of energy by particles also created confusion among the students. Nevertheless, the percentage was very small, only 0.93 percent. The alternative framework was expressed by the students when discussing the answers as follows:

The gas particles start absorbing energy as they are being liquefied

(Students aged 16-17 years)

Based on these answers, it was clear that the alternative framework was expressed by the students on the aspect of energy absorption. Students were confused by this aspect when assuming the gas particles absorbed the heat energy when the process of condensation occurred. These students' confusion was related to the concept of heat energy that moved the particles in matter. Therefore changes in the states of matter can occur through the heating or cooling processes, namely when the heat energy is absorbed or released from matter. For the process of 
condensation which was during the cooling process, the heat would be released from matter and particles of gas lost their energy and moved slower. The alternative framework of this aspect occurred due to the difficulty of the students to accept the situation that they had to use the ideas of particles to describe the characteristics of the macroscopic level (Beerenwinkel et al., 2011).

\subsubsection{The Confusions on the Attraction Forces between the Particles}

The final alternative framework of the students discussed in this study was the confusion on the attraction forces between the particles with the percentage of 0.31 percent. The example of the student's alternative framework is as follows:

Because the heat absorbed is used to overcome the force between the particles

(Students aged 16-17 years)

From the explanation mentioned, the failure of the students to master the concept of attraction forces between particles is clearly seen. This is consistent with the study by Dow, Auld and Wilson (1978), which realized that many students did not have the knowledge on the concept of forces in the states of solid, liquid and gas. In addition, this finding also answered and supported the finding on why many students did not use the idea of forces between particles when explaining the phenomena of condensation at the submicroscopic level. The study by Treagust et al. (2011) also found that many students were confused with the attraction forces of intramolecular and intermolecular. For instance when naphthalene was heated, it would melt because the heat energy absorption weakened the intermolecular forces between the molecules of naphthalene. It was not surprising when all the samples (students from form 4, 6, education degree with primary school science and bachelor of education) except for those with the specialization in biology who had the alternative framework with the belief that the energy absorbed was used to break the bonds/intramolecular forces in naphthalene. Only 31 percent of the students answered the items correctly to prove the understanding that the intermolecular forces must be overcome in order for the change to occur from the solid state to the liquid and eventually to gas. This alternative framework is also available widely in other studies such as the study by Tan and Treagust (1999).

\section{Conclusions}

The findings of this study indicated that the alternative frameworks of the students on the concept of condensation at the submicroscopic level from the aspect of explanations are divided into three categories namely the explanations with the alternative frameworks at the submicroscopic level, the limited explanations at the macroscopic level and no explanation. The explanations with alternative frameworks at submicroscopic level can be broken down into 10 sub-categories namely the answers which included the formation of molecules caused by the combinations between the particles and not by the formation of bonds, the air particles change into liquid, the alternative framework from the aspect of movement of particles, the confusion about the characteristics of matter, the change of phase from gas to liquid due to the bond cleavage, reducing number of particles, the particles become compressed and gathered in one area, the distance between the liquid particles is far, condensation as the energy absorption by particles and the confusion on the attraction forces between the particles. These findings showed that the students have ideas and knowledge about the process of condensation, but the inability of the students to master the submicroscopic level causes the explanations of the students to have the characteristics of alternative frameworks. This is because the submicroscopic level that cannot be seen has become a challenging perspective to the students and there are many studies in the literature which reported on the students' aspects of matter (Novick \& Nussbaum, 1981; Stavy, 1990; Liu, 2001) which can be expressed as a set of statements describing the behaviour of the particles at the submicroscopic level (de Vos \& Verdonk, 1996; Ayas et al., 2010).

The study also revealed that out of the ten sub-categories, the majority of secondary school students have the tendencies to give the answers on the formation of molecules caused by combinations between the particles and not by the formation of bonds and the air particles change into liquid. These alternative frameworks are giving little consideration to the aspects of attraction forces between particles and the distance between particles and mix the thinking of macroscopic level with the thinking of submicroscopic level when discussing the process of condensation. This finding has also been reported previously in the literature of which the students mixed the thinking of macroscopic level with the submicroscopic level when considering Melting Cycle Instruments (Smith \& Villarreal, 2015). This finding showed that students are still weak and lack knowledge of the concept of condensation at the submicroscopic level. By realizing this situation, the teachers should play greater roles during learning sessions by focusing on the submicroscopic level. 


\section{Implications}

The findings showed that more effective teaching methods should be developed to help students master the concepts of chemistry at submicroscopic level. Therefore teachers should pay more attention to the submicroscopic level of both aspects of explanations and drawings during the process of teaching and learning since the students' mastery on this level indicated that it has the characteristics of alternative frameworks. For example, the teachers can use the molecular simulations such as Processing (Fry \& Raes, 2001) and NetLogo (Wilensky, 1999) during the teaching and learning in order to emphasize to students the aspects of submicroscopic level. This method is important in ensuring the students' understandings of the concepts of science are becoming more scientific and the existence of alternative frameworks among the students can be reduced. In addition, teachers also have the role of providing more open-ended questions rather than the multiple-choice questions to stimulate students' thinking and prevent the students from remembering and memorizing the facts alone. This is important as the open-ended questions require students to explain the phenomena and chemical reactions in greater depth. The open-ended questions which are constructed and provided also require students to provide answers of both aspects of explanations and drawings at the submicroscopic level. This is because a good understanding of the scientific concept at submicroscopic level requires students to be able to provide scientific explanations and drawings.

\section{References}

Abraham, M. R., Grybowski, E. B., Renner, J. W., \& Marek, E. A. (1992). Understanding and misunderstanding of eighth graders of five chemistry concepts found in textbooks. Journal of Research in Science Teaching, 29, 105-120. http://dx.doi.org/10.1002/tea.3660290203

Abraham, M. R., Williamson, V. M., \& Westbrook, S. L. (1994). A cross-age study of the understanding of five chemistry concepts. Journal of Chemical Education, 31(2), 174-164. http://dx.doi.org/10.1002/tea.3660310206

Ardac, D., \& Akaygun, S. (2004). Effectiveness of multimedia-based instruction that emphasizes molecular representations on students' understanding of chemical change. Journal of Research in Science Teaching, 41(4), 317-337. http://dx.doi.org/10.1002/tea.20005

Ayas, A., \& Ozmen, H. (2002). A study of students' level of understanding of the particulate nature of matter at secondary school level. Bogazici University Journal of Education, 19(2), 45-60.

Ayas, A., Ozmen, H., \& Çalýk, M. (2010). Students' conception of the particulate nature of matter at secondary and tertiary level. International Journal of Science and Mathematics Educations, 8, 165-184. http://dx.doi.org/10.1007/s10763-009-9167-x

Baker, V., \& Millar, R. (2000). Students' reasoning about basic chemical thermodynamics and chemical bonding: what changes occur during a context-based post-16 chemistry course? International Journal of Science Education, 22(11), 1171-1200. http://dx.doi.org/10.1080/09500690050166742

Bar, V., \& Travis, A. S. (1991). Children's views concerning phase changes. Journal of Research in Science Teaching, 28(4), 363-382. http://dx.doi.org/10.1002/tea.3660280409

Beernwinkel, A., Parchmann, I., \& Grasel, C. (2011). Conceptual change texts in chemistry teaching: A study on the particle model of matter. International Journal of Science and Mathematics Education, 9, 1235-1259. http://dx.doi.org/10.1007/s10763-010-9257-9

Boo, H. (1998). Students' understanding of chemical bonds and the energetics of chemical reactions. Journal of $\begin{array}{llll}\text { Science } \quad \text { Education } & \text { Technology, }\end{array}$ http://dx.doi.org/10.1002/(sici)1098-2736(199805)35:5\%3C569::aid-tea6\%3E3.0.co;2-n

Chang, J. (1999). Teachers college students' conceptions about evaporation, condensation and boiling. Science Education, 83(5), 511-526. http://dx.doi.org/10.1002/(SICI)1098-237X(199909)83:5\%3C511::AID-SCE1\%3E3.0.CO;2-E

Coştu, B. (2008). Learning science through pdeode teaching strategy: Helping students' make sense of everyday situations. Eurasia Journal of Mathematics, Science \& Technology Education, 4(1), 3-9.

De Vos, W., \& Verdonk, A. H. (1987). A new road to reactions. Journal of Chemical Education, 64, 692-694. http://dx.doi.org/10.1021/ed064p692

Dow, W. M., Auld, J., \& Wilson, D. (1978). Pupils' concepts of solids, liquids and gases. Dundee: Dundee College of Education. 
Fraenkel, J. R., \& Wallen, N. E. (2008). How to design and evaluate research in education (7th ed.). New York: McGraw-Hill.

Fry, B., \& Raes, C. (2001). Processing (Version 2.0) [Computer Software]. Cambridge, MA: MIT.

Gabel, D. L., \& Samuel, K. V. (1987). Understanding the particulate nature of matter. Journal of Chemical Education, 64(8), 695-697. http://dx.doi.org/10.1021/ed064p695

Gopal, H., Kleinsmidt, J., \& Case, J. (2004). An investigation of tertiary students' understanding of evaporation, condensation and vapour pressure. International Journal of Science Education, 26(13), 1597-1620. http://dx.doi.org/10.1080/09500690410001673829

Haidar, A. H., \& Abraham, M. R. (1991). A comparison of applied and theoretical knowledge of concepts based on the particulate theory of matter. Journal of Research in Science Teaching, 28(10), 919-938.

Hatzinikita, V., \& Koulaidis, V. (1997). Pupils' ideas on conservation during changes in the state of water. Research in Science and Technological Education, 15(1), 53-71. http://dx.doi.org/10.1080/0263514970150104

Hittleman, D. R., \& Simon, A. J. (2002). Interpreting Educational Research: An Introduction for Consumers of Research. Upper Saddle River, N.J.: Merrill.

Johnson, P. (1998). Progression in children's understanding of a basic particle theory: A longitudinal study. International Journal of Science Education, 20, 393-412. http://dx.doi.org/10.1080/0950069980200402

Johnson, P. (2005). The development of children's concepts of a substance: A longitudinal study of interaction between curriculum and learning. Research in Science Education, 35, 41-61. http://dx.doi.org/10.1007/s11165-004-3432-3

Johnston, K. (1990). Students' responses to the active learning approach to teaching the particulate theory of matter. In P. L.Lijnse, P. Licht, W. de Vos, \& A. J. Waarlo (Eds.), Relating Macroscopic Phenomena to Microscopic Particles (pp. 247-265). Utrecht, The Netherlands: Centre for Science and Mathematics Education.

Kirbulut, Z. D., \& Beeth, M. E. (2013). Consistency of students' ideas across evaporation, condensation and boiling. Research in Science Education, 43, 209-232. http://dx.doi.org/10.1007/s11165-011-9264-z

Kruger, C. J., \& Summers, M. K. (1989). An investigation of some primary teachers' understanding of change in materials. School Science Review, 71(255), 12-27.

Lee, O., Eichinger, D. C., Anderson, C. W., Berkheimer, G. D., \& Blakeslee, T. D. (1993). Changing middle school students' conceptions of matter and molecules. Journal of Research in Science Teaching, 30, 249-270. http://dx.doi.org/10.1002/tea.3660300304

Liu, X. (2001). Synthesizing research on students conceptions in science. International Journal of Science Education, 23(1), 55-81. http://dx.doi.org/10.1080/09500690119778

Mitchell, A. C., \& Kellington, S. H. (1982). Learning difficulties associated with the particulate theory of matter in the Scottish integrated science course. European Journal of Science Education, 4(4), 429-440. http://dx.doi.org/10.1080/0140528820040409

Novick, S., \& Nussbaum, J. (1981). Pupil's understanding of the particulate nature of matter: A cross-age study. Science Education, 65(2), 187-196. http://dx.doi.org/10.1002/sce.3730650209

Paik, S.-H., Kim, H.-N., Cho, B.-K., \& Park, J.-W. (2004). K-8th grade Korean students' "conceptions of changes of state" and "conditions for changes of state". International Journal of Science Education, 26(2), 207-224. http://dx.doi.org/10.1080/0950069032000052063

Pereira, M. P., \& Pestana, M. E. M. (1991). Pupils' Representations of Models of Water. International Journal of Science Education, 13(3), 313-319. http://dx.doi.org/10.1080/0950069910130309

Scott, P. H. (1992). Pathways in learning science: a case study of the development of one student's ideas relating to the structure of matter. In R. Duit, F. Goldberg, \& H. Niedderer (Eds.), Research in Physics Learning: Theoretical Issues and Empirical Studies (pp. 203-224). Kiel, Germany: Institute for Science Education at the University of Kiel.

Smith, K. C., \& Villarreal, S. (2015). Using animations in identifying general chemistry students' misconceptions and evaluating their knowledge transfer relating to particle position in physical changes. Chemistry Education Research and Practice, 16, 273-282. http://dx.doi.org/10.1039/C4RP00229F 
Stavy, R. (1990). Children's conception of changes in the state of matter: from liquid (or solid) to gas. Journal of Research in Science Teaching, 27(3), 247-266. http://dx.doi.org/10.1002/tea.3660270308

Taber, K. S. (2001). Shifting sands: A case study of conceptual development as competition between alternative conceptions. International Journal of Science Education, 23(7), 731-753. http://dx.doi.org/10.1080/09500690010006572

Tan, D. K., \& Treagust, D. F. (1999). Evaluating students' understanding of chemical bonding. School Science Review, 81(294), 75-84.

Treagust, D. F., Chandrasesaran, A. L., Zain, A. N. M., Ong, E. T., Karpudewan, M., \& Halim, L. (2011). Evaluation of an intervention instructional program to facilitate understanding of basic particle concepts among students enrolled in several levels of study. Chemistry Education Research and Practice, 12, 251-261. http://dx.doi.org/10.1039/C1RP90030G

Varelas, M., Pappas, C. C., \& Rife, A. (2006). Exploring the role of intertextuality in concept construction: urban second graders make sense of evaporation, boiling and condensation. Journal of Research in Science Teaching, 43(7), 637-666. http://dx.doi.org/10.1002/tea.20100

Wilensky, U. (1999). NetLogo (Version 3.0). [Computer Program]. Evanston, IL: Center for Connected Learning and Computer Based Modelling, Northwestern University.

Yalçinkaya, E., \& Boz, Y. (2015). The effect of case-based instruction on 10th grade students' understanding of gas concepts. Chemistry Education Research and Practice, 1(16), 104-120.

Kheng, Y. T. (2011). Longman Essential Chemistry Form 4 Bilingual Text. Petaling Jaya: Pearson Malaysia Sdn Bhd. http://dx.doi.org/10.1039/C4RP00156G

\section{Copyrights}

Copyright for this article is retained by the author(s), with first publication rights granted to the journal.

This is an open-access article distributed under the terms and conditions of the Creative Commons Attribution license (http://creativecommons.org/licenses/by/3.0/). 